\title{
XPS and Water Contact Angle Measurements on Aged and Corona-Treated PP
}

\author{
S. SÜZER, ${ }^{1}$ A. ARGUN, ${ }^{1}$ O. VATANSEVER, ${ }^{2}$ O. $\operatorname{ARAL}^{2}$ \\ ${ }^{1}$ Bilkent University, Chemistry Department, 06533 Ankara, Turkey \\ 2 Polinas A.S., 45030 Manisa, Turkey
}

Received 12 March 1999; accepted 18 April 1999

\begin{abstract}
Effects of corona treatment and aging on commercially produced corona discharged polypropylene (PP) films were followed via surface sensitive roughness analysis by atomic force microscopy (AFM), water contact angle (WCA), and X-ray photoelectron spectroscopic (XPS) measurements. Roughness analysis by AFM gave similar results for both untreated and corona-treated samples. The measured water contact angle decreased after corona treatment but increased with aging. XPS findings revealed that corona treatment caused an increase in the O-containing species on the surface of the films, but the measured $\mathrm{O} / \mathrm{C}$ atomic ratio decreased with aging. The angle dependence of the observed XPS O/C atomic ratio further revealed that surface modifications by the corona treatment were buried into the polymer away from the surface as a function of aging. This is attributed to a surface rearrangement of the macromolecules in agreement with the findings of Garbassi et al. on oxygen-plasma-treated polypropylene. (C) 1999 John Wiley \& Sons, Inc. J Appl Polym Sci 74: 1846-1850, 1999
\end{abstract}

Key words: water contact angle; XPS; corona-treated-PP; aging

\section{INTRODUCTION}

Polypropylene, $\mathrm{PP}$, is one of the common commodity polymers with very wide applications, but has a very low surface energy (ca. $30-35 \mathrm{~mJ} / \mathrm{m}^{2}$ ) to be of any use for certain applications. ${ }^{1}$ The industrially adapted corona discharge treatment of polypropylene causes surface modifications leading to improvement in the wettability, printability, and other related surface properties of these materials. ${ }^{2}$ It is also well established that these surface modifications are degraded in time. ${ }^{3}$ The mechanism of the surface modifications and factors affecting it has been the subject of numerous publications. Surface sensitive techniques like

Correspondence to: S. Süzer.

Contract grant sponsor: TUBITAK; contract grant number TBAG-COST-1.

Journal of Applied Polymer Science, Vol. 74, 1846-1850 (1999)

(C) 1999 John Wiley \& Sons, Inc.

CCC 0021-8995/99/071846-05 contact-angle measurements, X-ray Photoelectron Spectroscopy (XPS), and Secondary Ion Mass Spectrometry (SIMS) have particularly been invaluable in elucidating these factors. A detailed review of the findings using core-level XPS analysis was given by Brewis and Briggs. ${ }^{4,5}$ In 1991, the same group reported on the information derivable form the valence band XPS analysis. ${ }^{6}$ Garbassi et al. reported on XPS, SSIMS, and contact-angle measurements of the surface modifications of oxygen-plasma-treated polypropylene, and especially on the effect of aging on these surface modifications. ${ }^{7,8}$ In particular, their measurements on ${ }^{18} \mathrm{O}_{2}$ plasma-treated $\mathrm{PP}$ revealed that when contacted with air, the polymer surface layer rearranges by macromolecular motions within itself. These motions are thermally activated with an apparent activation energy of 58.1 $\mathrm{kJ} / \mathrm{mol}$. Strobel et al. compared the various gas phase methods of modifying polymer surfaces us- 


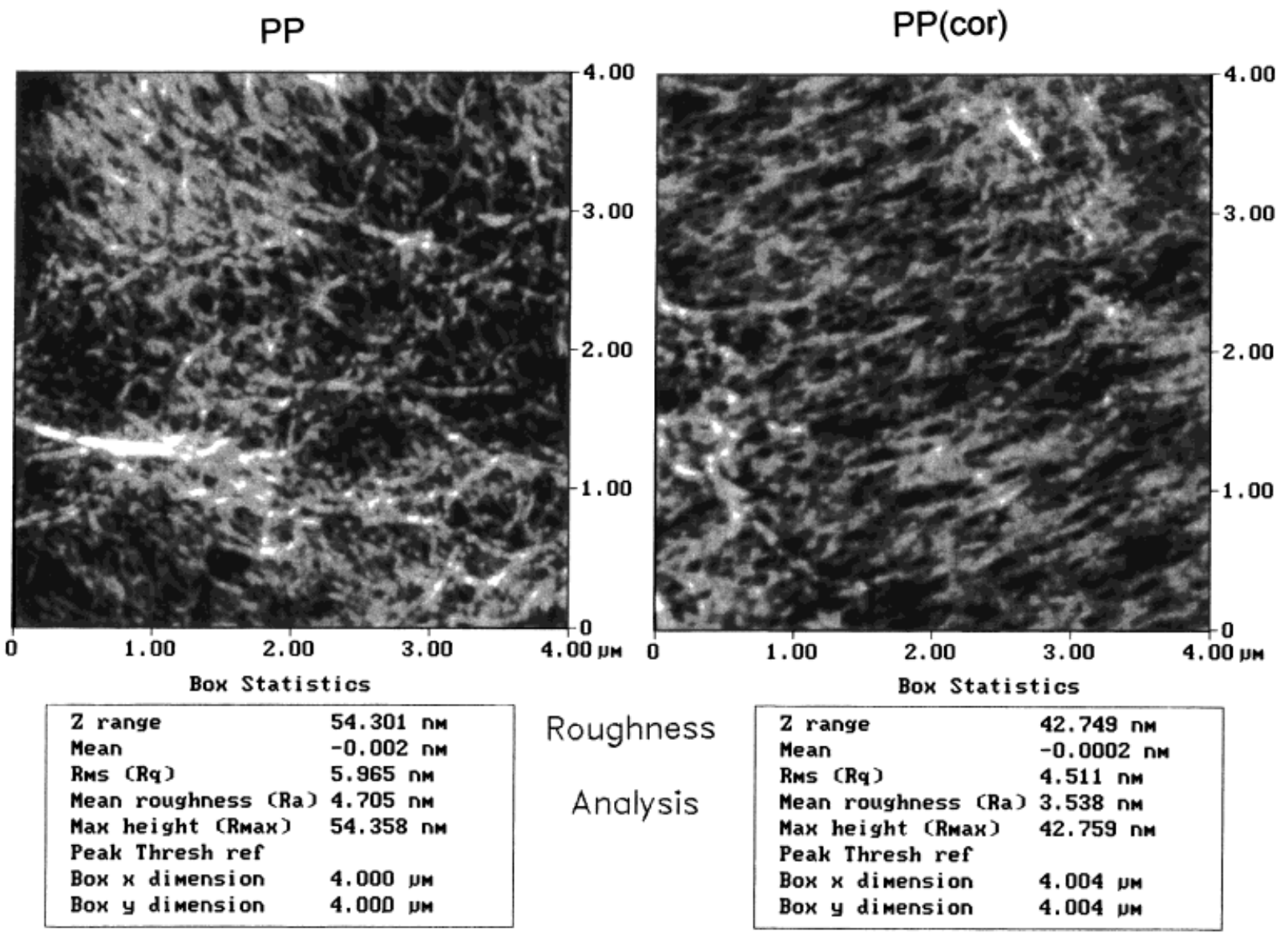

Figure 1 AFM images for roughness analysis of untreated and corona-treated PP.

ing XPS, FTIR, and contact angle measurements, ${ }^{9}$ and Greenwood et al. reported on characterization of silent discharge vs. low-pressure plasma treatment of various polymers including polypropylene using XPS and AFM. ${ }^{10}$ In a very recent article Boyd et al. reported on atmospheric non equilibrium plasma treatment of polypropylene using XPS, NMR, TOF-SIMS, and AFM techniques. ${ }^{11}$

Most of the previous studies are laboratory studies on systems applying the corona/plasma treatment. Although they reveal important information related to the mechanism of the treatment processes, most of the times the samples are overtreated to ensure the observation of the pursued effect. As a result of our ongoing efforts in understanding the mechanism of corona surface modifications of our own products, we have conducted a series of variable angle XPS (both core levels and valence band region), water contact angle, and roughness measurements using images obtained by atomic force microscopy (AFM). In this contribution we report our findings on our commercially produced and aged PP films.

\section{EXPERIMENTAL}

All of the PP films reported in this work were 20 $\mu \mathrm{m}$-thick commercial products, produced by Polinas A.Ş. Aging was carried out at $45^{\circ} \mathrm{C}$ and $60 \%$ relative humidity. AFM images were recorded by a Digital Instruments Nanoscope II STM Probe, operating in the tapping mode. XPS measurements were conducted on a Kratos ES300 Electron Spectrometer using $\mathrm{MgK} \alpha \mathrm{X}$-rays at 1253.6 $\mathrm{eV}$ at two different electron take-off angles. Surface energies were determined by recording the advancing contact angle of a sessile drop of deionized water on a Cam-Micro contact-angle meter produced by Tantec Inc. Multiple determination were carried out to ensure reproducibility.

\section{RESULTS}

\section{Roughness Measurements}

To differentiate between the physical/morphological and chemical changes on the surfaces of the 


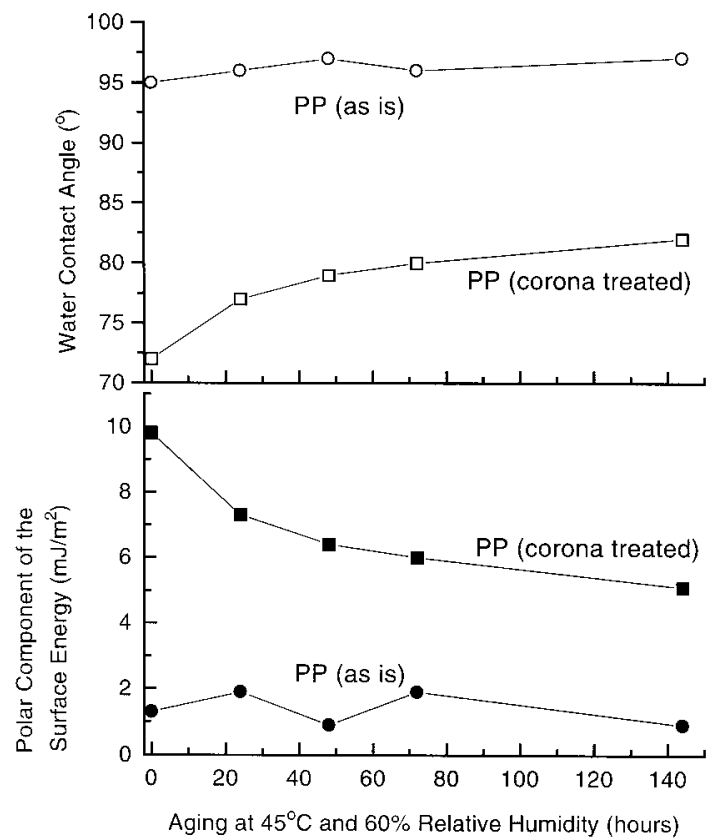

Figure 2 Measured advancing water contact angles of untreated and corona-treated PP as a function of aging at $45^{\circ} \mathrm{C}$ and $60 \%$ relative humidity. The bottom part of the figure gives the computed polar component of the surface energy.

corona-treated films we had reproduced AFM images of the films. Figure 1 depicts the roughness analysis of our untreated and corona-treated 20 $\mu \mathrm{m}$-thick commercial PP films. As far as roughness was concerned, no difference could be detected. Hence, we join the view that the surface modification caused by high-voltage corona treatment of PP in air is predominantly related to chemical changes. ${ }^{4-11}$

\section{Water-Contact Angle Measurements}

The measured value of the water-contact angle of the untreated $\mathrm{PP}$ is $95^{\circ}$, and increases slightly as a result of aging. The corona treatment causes a reduction in the measured water contact angle, which returns to its original values with aging, as depicted by Figure 2. Figure 2 also displays the change in the polar component of the surface energy of the polymer calculated using the Fowkes approximation: ${ }^{12}$

$$
(1+\cos \theta) \gamma_{L}=2\left(\gamma_{S}^{d} \gamma_{L}^{d}\right)^{1 / 2}+2\left(\gamma_{S}^{p} \gamma_{L}^{p}\right)^{1 / 2}
$$

where $\theta$ is the measured contact angle, $\gamma_{L}$ is the surface energy of the liquid (i.e., water, taken as $72.8 \mathrm{~mJ} / \mathrm{m}^{2}$ ), and $\gamma_{L}^{d}$ and $\gamma_{L}^{p}$ are the dispersion and polar components (taken as 21.8 and 51.0 $\mathrm{mJ} / \mathrm{m}^{2}$, respectively). ${ }^{13}$ The surface energy of the solid $\gamma_{S}$ and its components, $\gamma_{S}^{d}$ and $\gamma_{S}^{p}$ are best determined by using two liquids approach of Llyod et al. ${ }^{14}$ However, a rough estimate of the polar component of the surface energy can be obtained using the measured contact angle values by taking the dispersion component to be 30.0 $\mathrm{mJ} / \mathrm{m}^{2}$ for the untreated polypropylene and assuming that it does not change either as the result of corona treatment or aging (Table I).

\section{XPS Measurements}

Figure 3 displays parts of the XPS spectra recorded by $\mathrm{MgK} \alpha$ X-rays $(1253.6 \mathrm{eV})$ of the untreated and corona-treated PP films before and after $48 \mathrm{~h}$ of aging at two electron take-off angles. Corona treatment caused an increase in the bandwidth of the C1s peak together with the appearance of weak additional peaks at a higher binding energy side, and more importantly, almost an order of magnitude increase on the O1s peak intensity, which became even stronger at the lower takeoff angle. Aging caused a slight decrease in the O1s signal, but the angle dependence became less pronounced. Similar changes were also observed in the valence-band region, as shown in Figure 4.

Table I Advancing Water Contact Angle Values and XPS O/C Atomic Ratios at $90^{\circ}$ and $30^{\circ}$ Electron Take-Off Angles Together with the Computed Polar Component of the Surface Energy of Untreated and Corona-Treated PP Aged at $45^{\circ} \mathrm{C}$ and $60 \%$ Relative Humidity

\begin{tabular}{|c|c|c|c|c|}
\hline & \multirow{2}{*}{$\begin{array}{c}\text { a WCA } \\
\left(^{\circ}\right)\end{array}$} & \multicolumn{2}{|c|}{${ }^{\mathrm{b}} \mathrm{O} / \mathrm{C}$ Ratio } & \multirow{2}{*}{$\begin{array}{c}{ }^{\mathrm{c}} \gamma_{S}^{p} \\
\left(\mathrm{~mJ} / \mathrm{m}^{2}\right)\end{array}$} \\
\hline & & $\left(90^{\circ}\right)$ & $\left(30^{\circ}\right)$ & \\
\hline $\mathrm{PP}$ & 95 & 0.02 & 0.06 & 1.3 \\
\hline $\mathrm{PP}$ (cor.) & 72 & 0.12 & 0.25 & 9.8 \\
\hline $\mathrm{PP}(24 \mathrm{~h})$ & 96 & 0.02 & 0.06 & 1.9 \\
\hline $\mathrm{PP}($ cor. $+24 \mathrm{~h})$ & 77 & 0.13 & 0.20 & 7.3 \\
\hline PP (48 h) & 97 & 0.02 & 0.07 & 0.9 \\
\hline $\mathrm{PP}($ cor. $+48 \mathrm{~h})$ & 79 & 0.13 & 0.17 & 6.4 \\
\hline $\mathrm{PP}(72 \mathrm{~h})$ & 96 & 0.02 & 0.06 & 1.9 \\
\hline $\mathrm{PP}($ cor. $+72 \mathrm{~h})$ & 80 & 0.11 & 0.15 & 6.0 \\
\hline $\mathrm{PP}(144 \mathrm{~h})$ & 97 & 0.02 & 0.07 & 0.9 \\
\hline $\mathrm{PP}($ cor. $+144 \mathrm{~h})$ & 82 & 0.10 & 0.15 & 5.1 \\
\hline \multicolumn{5}{|c|}{$\begin{array}{l}\text { a The estimated uncertainty in WCA is about } \pm 3^{\circ} \text {. } \\
\text { b The estimated uncertainty in XPS atomic ratio is less } \\
\text { than } \pm 20 \% \text {. } \\
\text { c Calculated from the measured WCA and using Fowkes } \\
\text { approach and assuming a constant } 30.0 \mathrm{~mJ} / \mathrm{m}^{2} \text { dispersion } \\
\text { component. }{ }^{12}\end{array}$} \\
\hline
\end{tabular}




\section{DISCUSSION}

Our AFM roughness measurements reveal that the commercially used corona-treatment causes no significant physical/morphological changes (in the $\mathrm{nm}$ scale) on the polymer surfaces in contrast to the results reported in refs. 10 and 11 . The difference must be related to the extent of the corona/plasma treatment. The samples reported in refs. 10 and 11 were subjected to a minimum of a 30 -s plasma treatment, which resulted in a very high $\mathrm{O} / \mathrm{C}$ atomic ratio as determined by XPS. Their reported minimum $\mathrm{O} / \mathrm{C}$ atomic ratio is 0.29 . This is approximately three times larger than our measured $\mathrm{O} / \mathrm{C}$ ratio. Hence, the samples used in refs. 10 and 11 are overtreated and cannot be compared with the commercial ones. Similar arguments also follow in comparing the results of water contact angles and XPS measurements. For example, the water contact angle of the plasmatreated sample reported in refs. 7 and 8 is $24^{\circ}$, which is too low compared to any commercially corona-treated PP (typical values are $70-75^{\circ}$ ). However, the results reported in ref. 7, 8, 10, and 11 are extremely important for elucidating the mechanism of corona/plasma treatment and especially of aging. Our water contact angle measurements, together with the XPS results at two elec-

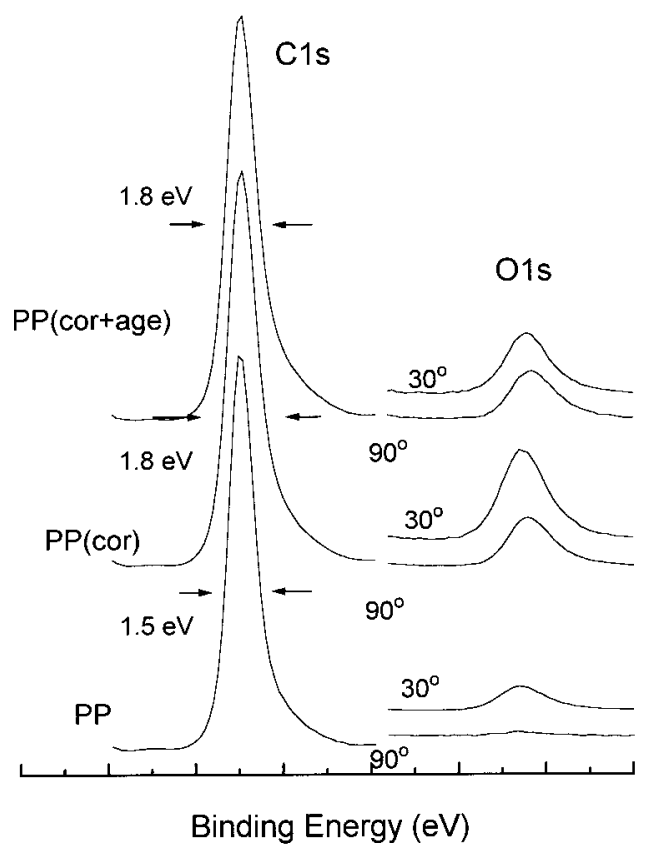

Figure 3 Part of the MgK $\alpha$ XPS spectra of untreated $\mathrm{PP}$ and corona-treated PP before and after $48 \mathrm{~h}$ aging recorded at 90 and $30^{\circ}$ electron take-off angles.

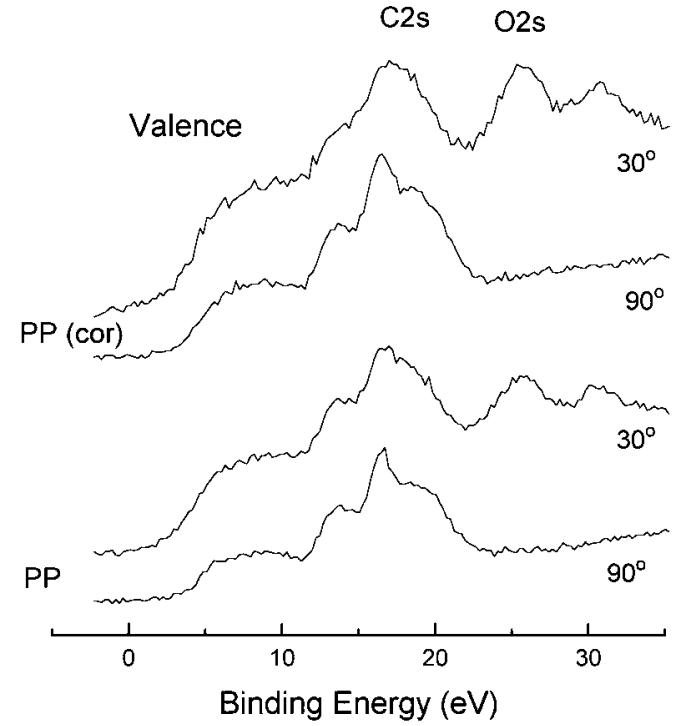

Figure 4 Valence-band $\operatorname{MgK} \alpha$ XPS spectra of untreated and corona-treated $\mathrm{PP}$ recorded at 90 and $30^{\circ}$ electron take-off angles.

tron take-off angles, are in complete agreement with results reported in refs. 7 and 8 . Hence, the surface modification as a result of the commercially adapted corona-treatment is also mainly due to the introduction of polar groups initially concentrated on the few atomic layers $(0-4 \mathrm{~nm})$, as evidenced by the increase in the $\mathrm{O} / \mathrm{C}$ ratio at the lower electron take-off angle determined by XPS. These polar groups spread down into the bulk as a function of aging, which was also evidenced by the weaker angular dependence of the $\mathrm{O} / \mathrm{C}$ ratio determined by XPS. This must also be the result of the thermodynamical force to attain the minimum surface energy. ${ }^{7,8}$

We are grateful to Dr. C. M. Younes of the Interface Analysis Centre of University of Bristol, UK, for the AFM images. This work is partly supported by TUBITAK, the Scientific and Technical Research Council of Turkey through Grant TBAG-COST-1.

\section{REFERENCES}

1. Wu, S. Polymer Interface and Adhesion; Marcel Dekker: New York, 1982.

2. Boenig, H. V. Plasma Science and Technology; Cornell University Press: Ithaca, NY, 1982.

3. Yasuda, H.; Sharma, H. K.; Yasuda, T. J Polym Sci Phys Ed 1981, 19, 1285.

4. Blythe, A. R.; Briggs, D.; Kendall, C. R.; Rance, D. G.; Zichy, V. J. I. Polymer 1978, 19, 1273. 
5. Brewis, D. M.; Briggs, D. Polymer 1981, 22, 7.

6. Foerch, R.; Beamson, G.; Briggs, D. Surface Interface Anal 1991, 17, 842.

7. Garbassi, F.; Morra, M.; Occhiello, E.; Barino, L.; Scordamaglia, R. Surface Interface Anal 1989, 14, 585.

8. Occhiello, E.; Morra, M.; Morini, G.; Garbassi, F.; Humphrey, P. J Appl Polym Sci 1991, 42, 551.

9. Strobel, M.; Walzak, M. J.; Hill, J. M.; Lin, M.; Karbashewski, E.; Lyons, C. S. In Polymer Surface Modification: Relevance to Adhesion; Mittal, K. L., Ed.; VSP: Zeist, The Netherlands, 1994, p. 233.
10. Greenwood, O. D.; Boyd, R. S.; Hopkins, J.; Badyal, J. P. S. In Polymer Surface Modification: Relevance to Adhesion; Mittal, K. L., Ed.; VSP: Zeist, The Netherlands, 1994, p. 17.

11. Boyd, R. D.; Kenwright, A. M.; Badyal, J. P. S.; Briggs, D. Macromolecules 1997, 30, 5429.

12. Fowkes, F. M. J Phys Chem 1963, 67, 2538.

13. Owens, D. K.; Wendt, R. C. J Appl Polym Sci 1969, 13, 1741 .

14. Lloyd, T. B.; Ferretti, K. E.; Lagow, J. J Appl Polym Sci 1995, 58, 291. 